\title{
Simple phenomenological determination of contact stiffness and elastic modulus of Ce-based bulk metallic glasses through nanoindentation
}

\author{
W. H. Li ${ }^{\mathrm{a})}$ \\ School of Materials Science and Engineering, Anhui University of Technology, Maanshan 243002, \\ People's Republic of China
}

Keesam Shin and C. G. Lee

School of Nano and Advanced Materials, Changwon National University, 9 Sarim-dong, Changwon-city, Republic of Korea

B. C. Wei

National Microgravity Laboratory, Institute of Mechanics, Chinese Academy of Sciences, Beijing 100080, People's Republic of China

\section{T. H. Zhang}

State Key Laboratory of Nonlinear Mechanics, Institute of Mechanics, Chinese Academy of Sciences, Beijing 100080, People's Republic of China

(Received 4 February 2007; accepted 4 April 2007; published online 27 April 2007)

\begin{abstract}
The viscoelastic deformation of Ce-based bulk metallic glasses (BMGs) with low glass transition temperature is investigated at room temperature. Contact stiffness and elastic modulus of Ce-based BMGs cannot be derived using the conventional Oliver-Pharr method [W. C. Oliver and G. M. Pharr, J. Mater. Res. 7, 1564 (1992)]. The present work shows that the time dependent displacement of unloading segments can be described well by a generalized Kelvin model. Thus, a modified Oliver-Pharr method is proposed to evaluate the contact stiffness and elastic modulus, which does, in fact, reproduce the values obtained via uniaxial compression tests. (c) 2007 American Institute of Physics. [DOI: 10.1063/1.2734394]
\end{abstract}

Nanoindentation is a convenient method to determine mechanical parameters such as hardness and elastic modulus of materials in small volumes. The testing methodology given by Oliver and Pharr is the most widely used. ${ }^{1,2}$ In this method, the elastic modulus is obtained by assuming that the unloading segment is a purely elastic recovery process. However, for materials with time dependent deformations, this approximation leads to an overestimation of Young's modulus. In recent years, a number of authors ${ }^{3-10}$ have proposed various ways of improving analysis of indentation measurements in viscoelastic solids. There are two basic approaches. The first is experimental method to allow sufficient time at peak load to decrease the creep rate. ${ }^{11-13}$ However, this can introduce a thermal drift during the held load step. The second approach considers the data analysis, using several models based on viscoelastic theory. ${ }^{14-16} \mathrm{Up}$ to now, the majority of the work on viscoelastic deformation has been focused on polymer materials. They are, in contrast to bulk metallic glasses (BMGs), our field of interest, anisotropic and their macroscopic mechanical properties indentation is also different. Compared with polymers, BMGs, with their isotropic structure and wide supercooled liquid region, are easier to work with in nanoindentation experiments, to study creep and relaxation in the amorphous state. In this letter, the viscoelastic deformation of Ce-based BMGs with low glass transition temperature is investigated using nanoindentation. A modified Oliver and Pharr approximation is proposed to calculate the initial unloading slope and elastic modulus of Ce-based BMGs. The results are compared with values determined from compression tests.

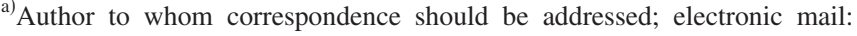
whli@imech.ac.cn
Two kinds of Ce-based BMGs, with the nominal composition of $\mathrm{Ce}_{68} \mathrm{Al}_{10} \mathrm{Cu}_{20} \mathrm{Nb}_{2}$ and $\mathrm{Ce}_{60} \mathrm{Al}_{15} \mathrm{Ni}_{15} \mathrm{Cu}_{10}$ (at. \%), were selected as the time dependent test materials. The alloys were prepared from a mixture of the pure elements by arcmelting. Cylindrical specimens of $3 \mathrm{~mm}$ in diameter and $70 \mathrm{~mm}$ in length were prepared by suction casting into a copper mold. The structure of the samples was characterized by x-ray diffraction and differential scanning calorimeter. Nanoindentation experiments were conducted at room temperature $(296 \mathrm{~K})$ using a commercial depth-sensing instrument (MTS Nano Indenter® XP). All the indentation experiments were performed with a Berkovich diamond indenter.

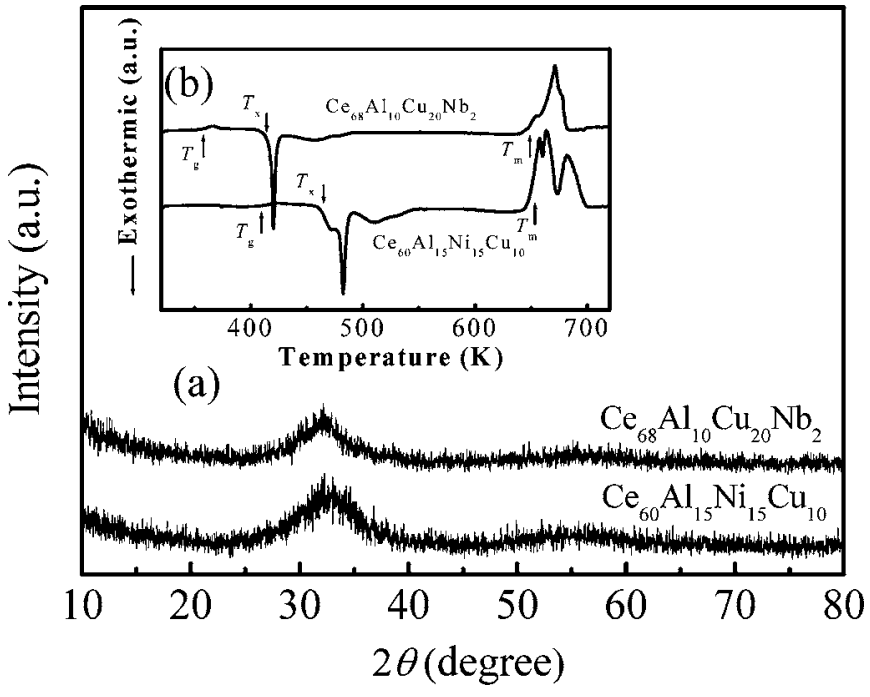

FIG. 1. (a) XRD patterns and (b) DSC curves of as-cast $\mathrm{Ce}_{68} \mathrm{Al}_{10} \mathrm{Cu}_{20} \mathrm{Nb}_{2}$ and $\mathrm{Ce}_{60} \mathrm{Al}_{15} \mathrm{Ni}_{15} \mathrm{Cu}_{10}$ alloys at a heating rate of $20 \mathrm{~K} / \mathrm{min}$. 


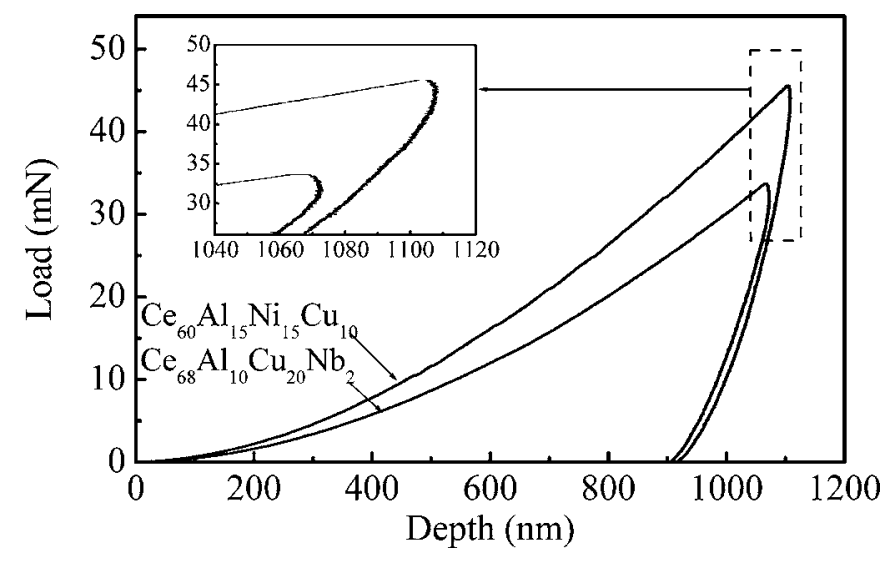

FIG. 2. Typical load-displacement $(P-h)$ curves of $\mathrm{Ce}_{68} \mathrm{Al}_{10} \mathrm{Cu}_{20} \mathrm{Nb}_{2}$ and $\mathrm{Ce}_{60} \mathrm{Al}_{15} \mathrm{Ni}_{15} \mathrm{Cu}_{10}$ BMGs during nanoindentation. The inset highlights the unloading segments.

The specimens were mechanically polished to a mirror finish. Fused silica was used as a reference sample for the initial tip calibration procedure. Experiments at constant loading rates of $0.03,0.075,0.2,0.5$, and $1 \mathrm{mN} / \mathrm{s}$ were performed to a depth limit of $1000 \mathrm{~nm}$, and the maximum load was held constant for $10 \mathrm{~s}$ and then was unloaded at the same rates as the loading one. Six indentations were made for each test on each specimen. The uniaxial compression tests on cylindrical samples of $3 \mathrm{~mm}$ in diameter and $5.8 \mathrm{~mm}$ in length were performed in an Instron-type testing machine at room temperature.

Figure 1 shows the $\mathrm{x}$-ray diffraction (XRD) patterns of as-cast $\mathrm{Ce}_{68} \mathrm{Al}_{10} \mathrm{Cu}_{20} \mathrm{Nb}_{2}$ and $\mathrm{Ce}_{60} \mathrm{Al}_{15} \mathrm{Ni}_{15} \mathrm{Cu}_{10}$ samples. Both as-cast alloys exhibit an XRD spectrum typical for an amorphous phase without an obvious crystalline peak. The inset in Fig. 1 shows the differential scanning calorimeter (DSC) curves of the two BMGs. The glass transition temperature $\left(T_{g}\right)$ of $\mathrm{Ce}_{68} \mathrm{Al}_{10} \mathrm{Cu}_{20} \mathrm{Nb}_{2}$ and $\mathrm{Ce}_{60} \mathrm{Al}_{15} \mathrm{Ni}_{15} \mathrm{Cu}_{10}$ BMGs is 359 and $400 \mathrm{~K}$, respectively. These values are in agreement with those obtained in Refs. 17-19.

Figure 2 shows typical load-displacement curves of the two BMGs at a loading rate of $0.03 \mathrm{mN} / \mathrm{s}$. The inset of Fig. 2 highlights the unloading segments. We can see that the indentation depth continues to increase at the beginning of unloading, resulting in a "nose" in the unloading curve. When the nose occurs, the contact stiffness at the initial unloading segment becomes negative, and the elastic modulus calculated by the method may be unreasonable. At an unloading rate of $0.03 \mathrm{mN} / \mathrm{s}$, the values of contact stiffness are

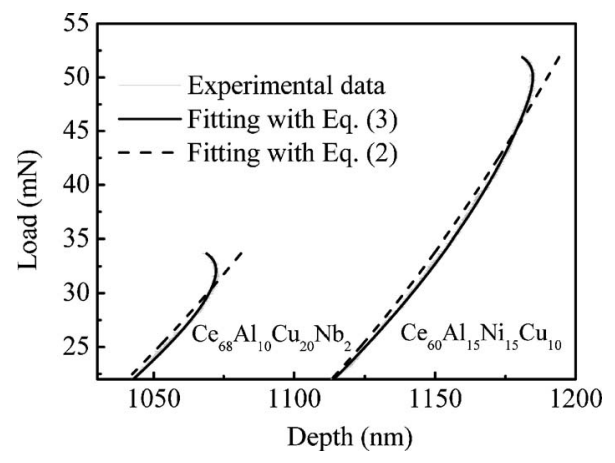

FIG. 3. Curve fitting of the unloading segment with the Oliver-Pharr approximation and the modified Oliver-Pharr approximation at an unloading

BMGs in compression test at a strain rate of $1.0 \times 10^{-4} \mathrm{~s}^{-1}$.
rate of $0.03 \mathrm{mN} / \mathrm{s}$.
Downloaded 24 Jul 2007 to 159.226.231.70. Redistribution subject to AIP license or copyright, see http://apl.aip.org/apl/copyright.jsp

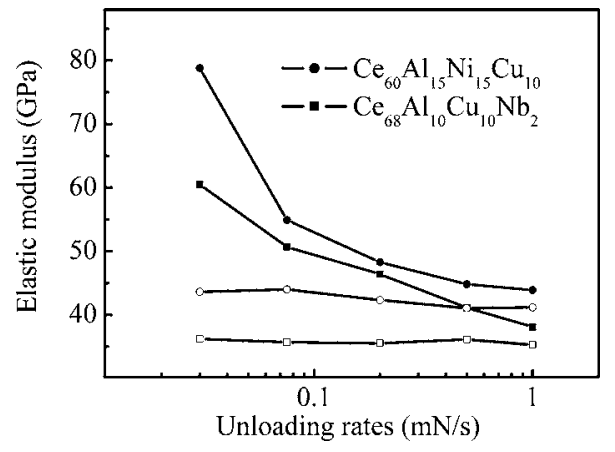

FIG. 4. Elastic modulus of $\mathrm{Ce}_{60} \mathrm{Al}_{15} \mathrm{Ni}_{15} \mathrm{Cu}_{10}$ and $\mathrm{Ce}_{68} \mathrm{Al}_{10} \mathrm{Cu}_{20} \mathrm{Nb}_{2}$ BMGs obtained using Oliver-Pharr (solid symbols) and modified Oliver-Pharr (open symbols).

0.41 and $0.53 \mathrm{mN} / \mathrm{nm}$ for $\mathrm{Ce}_{68} \mathrm{Al}_{10} \mathrm{Cu}_{20} \mathrm{Nb}_{2}$ and $\mathrm{Ce}_{60} \mathrm{Al}_{15} \mathrm{Ni}_{15} \mathrm{Cu}_{10}$ BMGs, respectively. Using the OliverPharr method with increasing unloading rates, the elastic modulus $(E)$ of $\mathrm{Ce}_{68} \mathrm{Al}_{10} \mathrm{Cu}_{20} \mathrm{Nb}_{2}$ and $\mathrm{Ce}_{60} \mathrm{Al}_{15} \mathrm{Ni}_{15} \mathrm{Cu}_{10}$ BMGs decreases from 60.5 and $78.8 \mathrm{GPa}$ to 38.1 and $43.9 \mathrm{GPa}$, respectively. The contact stiffness and elastic modulus of the two BMGs decrease gradually with increasing unloading rates. The decreasing elastic modulus is also found at high unloading rates in amorphous polymers; it is usually referred to as a restraining viscoelastic deformation. ${ }^{14}$ This indicates that the elastic modulus calculated by the Oliver-Pharr scheme is unsuitable for time dependent materials.

Wei et $a l^{20}{ }^{20}$ have considered indentation creep for the holding segment using a generalized Kelvin model. They obtained a creep rate and a creep retard spectrum for Cebased BMGs. The total displacement $h$ during the indentation creep is expressed by

$$
h=\sum_{i=1}^{n} h_{i}\left(1-e^{-t / \tau_{i}}\right),
$$

where $h_{e}$ is the indentation depth at the first spring, $h_{i}$ represents the indentation depth at the $i$ th Kelvin element, and $\tau_{i}$ is the retardation time for the $i$ th element. For the unloading process, the unloading curves include two parts, one is elastic recovery and the other is viscoelastic recovery. For the elastic recovery part we still use the Oliver-Pharr approximation, in which the load or depth can be expressed with a power law as

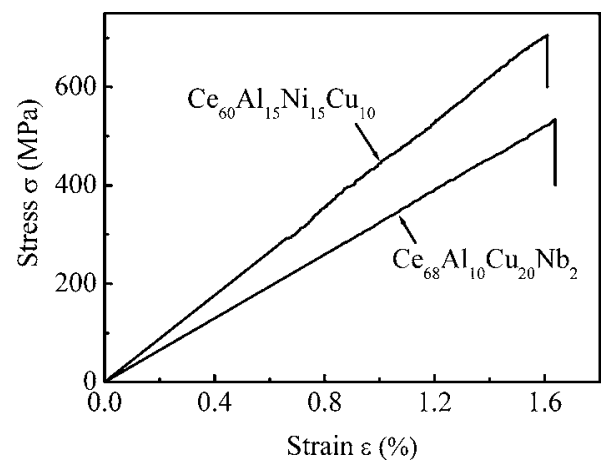

FIG. 5. Stress-strain curves of $\mathrm{Ce}_{68} \mathrm{Al}_{10} \mathrm{Cu}_{20} \mathrm{Nb}_{2}$ and $\mathrm{Ce}_{60} \mathrm{Al}_{15} \mathrm{Ni}_{15} \mathrm{Cu}_{10}$ BMGs in compression test at a strain rate of $1.0 \times 10^{-4} \mathrm{~s}^{-1}$.

BMGs in compression test at a strain rate of $1.0 \times 10^{-4} \mathrm{~s}^{-1}$.
AIP license or copyright, see http://apl.aip.org/apl/copyright.jsp 
TABLE I. Fitting parameters $h_{f}, A, n, K_{1}, \tau_{1}, K_{2}$, and $\tau_{2}$, and correlation coefficients of $\mathrm{Ce}_{68} \mathrm{Al}_{10} \mathrm{Cu}_{20} \mathrm{Nb}_{2}$ and $\mathrm{Ce}_{60} \mathrm{Al}_{15} \mathrm{Ni}_{15} \mathrm{Cu}_{10}$ alloys at unloading rate of $0.03 \mathrm{mN} / \mathrm{s}$.

\begin{tabular}{ccccccccc}
\hline \hline Alloys & $\begin{array}{c}h_{f} \\
(\mathrm{~nm})\end{array}$ & $A$ & $n$ & $\begin{array}{c}K_{1} \\
(\mathrm{mN} / \mathrm{nm})\end{array}$ & $\begin{array}{r}\tau_{2} \\
(\mathrm{~s})\end{array}$ & $\begin{array}{c}K_{2} \\
(\mathrm{~s})\end{array}$ & $\begin{array}{c}\tau_{2} \\
(\mathrm{~s})\end{array}$ & $\begin{array}{c}\text { Correlation } \\
\text { coefficient }\end{array}$ \\
\hline $\mathrm{Ce}_{68} \mathrm{Al}_{10} \mathrm{Cu}_{20} \mathrm{Nb}_{2}$ & 902 & 16.6 & 0.66 & 1.93 & 209.2 & 4.4 & 40.8 & 0.99976 \\
$\mathrm{Ce}_{60} \mathrm{Al}_{15} \mathrm{Ni}_{15} \mathrm{Cu}_{10}$ & 879 & 41.0 & 0.45 & 2.48 & 372.2 & 9.0 & 47.5 & 0.99977 \\
\hline \hline
\end{tabular}

$$
h=h_{f}+A P^{n},
$$

where $A, h_{f}$, and $n$ are empirical parameters. For the viscoelastic recovery part we adjust Eq. (1) in which time $(t)$ is a function of load $(P)$, namely, $t=\left(P_{m}-P\right) / \dot{P}$, where $P_{\max }$ is the initial load of the unloading stages and $\dot{P}$ is the unloading rate. Thus, the total displacement during unloading can be written as

$$
h=h_{f}+A P^{n}+\sum_{i=1}^{n} \frac{P}{K_{i}}\left(1-e^{-t / \tau_{i}}\right) .
$$

The indentation unloading curves of our Ce-based BMGs and the fitting curves derived from Eqs. (2) and (3) are shown in Fig. 3. The fitting parameters of Eq. (3) are summarized in Table I. Note the excellent correlation coefficients. From Fig. 3 we can see that the results using our method are in much better agreement with the experimental data than those of the Oliver-Pharr approximation alone. By fitting Eq. (3) to the experimental unloading curves, the contact stiffness, $S=(d P / d h)_{m}$, can be deduced. Based on elastic solutions by Sneddon ${ }^{21}$ and the Oliver-Pharr method, the elastic modulus of the two Ce-based BMGs can be calculated. Figure 4 shows the calculated elastic moduli using our modified method and the Oliver-Pharr approximation at different loading rates. It can be seen that, when the simple Oliver-Pharr method is used, the elastic modulus decreases significantly with increasing loading rate. In contrast, the modulus calculated from our modified method is nearly independent of the unloading rates.

We also compare these values with those obtained from uniaxial compression curves (Fig. 5). Both BMGs exhibit complete elastic deformation followed by brittle fracture without viscoelastic deformation and global plasticity. Young's modulus $(E)$ and yield strength $(\sigma)$ of $\mathrm{Ce}_{68} \mathrm{Al}_{10} \mathrm{Cu}_{20} \mathrm{Nb}_{2}$ and $\mathrm{Ce}_{60} \mathrm{Al}_{15} \mathrm{Ni}_{15} \mathrm{Cu}_{10}$ BMGs are $32.2 \mathrm{GPa}$ and $534 \mathrm{MPa}$, and $42.4 \mathrm{GPa}$, and $705 \mathrm{MPa}$, respectively. The elastic modulus provides values that are similar to values using ultrasonic measurements method, which has been widely used to measure the elastic constants of bulk metallic glasses. $^{22,23}$ These results reveal that the modulus values calculated using our modified Oliver-Pharr method agree well with those determined by compression tests and ultrasonic measurements method. This suggests that our analysis method may be useful to derive the modulus of the time dependent materials.

In conclusion, the time dependent deformation of $\mathrm{Ce}$ based BMGs was studied by indentation. We propose a modified Oliver-Pharr approximation to the generalized Kelvin model to estimate the slope of the unloading curves and the elastic moduli of time dependent materials. The results show good agreement to those obtained from compression experiments and ultrasonic measurements method.

This research was carried out during a visit by the first of the authors to Changwon National University supported by the second stage of the Brain Korea 21 program. The authors would also like to acknowledge the support of the Korean Research Foundation, Grant (KRF-2006-005-J02703), the Nature Science Foundation of Anhui Educational Bureau (Grant No. KJ2007B273), and the National Natural Science Foundation of China (Grant No. 50571109).

${ }^{1}$ W. C. Oliver and G. M. Pharr, J. Mater. Res. 7, 1564 (1992).

${ }^{2}$ G. M. Pharr, W. C. Oliver, and F. B. Brotzen, J. Mater. Res. 7, 613 (1992).

${ }^{3}$ W. B. Li and R. Warren, Acta Metall. Mater. 41, 3065 (1993).

${ }^{4}$ P. M. Sargent and M. F. Ashby, Mat. Sci. Technol. 8, 594 (1992).

${ }^{5}$ L. Cheng, L. E. Scriven, and W. W. Gerberich, Mater. Res. Soc. Symp. Proc. 522, 193 (1998).

${ }^{6}$ A. Strojny and W. W. Gerberich, Mater. Res. Soc. Symp. Proc. 522, 159 (1998).

${ }^{7}$ J. C. M. Li, Mater. Sci. Eng., A 322, 23 (2002).

${ }^{8}$ M. L. Oyen and R. F. Cook, J. Mater. Res. 18, 139 (2003).

${ }^{9}$ Y. Shuang, Y. W. Zhang, and K. Y. Zeng, J. Appl. Phys. 95, 3655 (2004).

${ }^{10}$ A. C. Fishcher-Cripps, Nanoindentation (Springer, New York, 2000).

${ }^{11}$ G. Feng and A. H. W. Ngan, J. Mater. Res. 17, 660 (2002).

${ }^{12}$ A. H. W. Ngan and B. Tang, J. Mater. Res. 17, 2604 (2002).

${ }^{13}$ B. J. Briscoe, L. Fiori, and E. Pelillo, J. Phys. D 31, 2395 (1998).

${ }^{14}$ C. K. Liu, S. Lee, L. P. Sung, and T. Nguyen, J. Appl. Phys. 100, 033503 (2006).

${ }^{15}$ Y.-T. Cheng and C.-M. Cheng, Appl. Phys. Lett. 87, 111914 (2006).

${ }^{16}$ Y.-T. Cheng and C.-M. Cheng, Mater. Res. Soc. Symp. Proc. 84, 299 (2005).

${ }^{17}$ B. Zhang, M. X. Pan, D. Q. Zhao, and W. H. Wang, Appl. Phys. Lett. 85, 61 (2004).

${ }^{18}$ B. Zhang, R. J. Wang, D. Q. Zhao, M. X. Pan, and W. H. Wang, Phys. Rev. B 70, 224208 (2004).

${ }^{19}$ B. Zhang, R. J. Wang, D. Q. Zhao, M. X. Pan, and W. H. Wang, Phys. Rev. B 73, 092201 (2006).

${ }^{20}$ B. C. Wei, T. H. Zhang, W. H. Li, D. M. Xing, L. C. Zhang, and Y. R. Wang, Mater. Trans. 46, 2959 (2005).

${ }^{21}$ I. N. Sneddon, Int. J. Eng. Sci. 3, 47 (1965).

${ }^{22}$ W. H. Wang, J. Appl. Phys. 99, 093506 (2006).

${ }^{23}$ W. H. Wang, C. Dong, and C. H. Shek, Mater. Sci. Eng., R. 44, 45 (2004). 